\title{
Rapid evaporative ionisation mass spectrometry of electrosurgical vapours for the identification of breast pathology: towards an intelligent knife for breast cancer surgery
}

Edward R. St John1', Julia Balog 2,3, James S. McKenzie², Merja Rossi ${ }^{2}$, April Covington'1, Laura Muirhead', Zsolt Bodai ${ }^{2}$, Francesca Rosini ${ }^{2,4}$, Abigail V. M. Speller ${ }^{2,4}$, Sami Shousha ${ }^{4}$, Rathi Ramakrishnan ${ }^{4}$, Ara Darzi ${ }^{1}$, Zoltan Takats ${ }^{2,5^{*}+}$ and Daniel R. Leff ${ }^{1,6^{*}+}$

\begin{abstract}
Background: Re-operation for positive resection margins following breast-conserving surgery occurs frequently (average $=20-25 \%$ ), is cost-inefficient, and leads to physical and psychological morbidity. Current margin assessment techniques are slow and labour intensive. Rapid evaporative ionisation mass spectrometry (REIMS) rapidly identifies dissected tissues by determination of tissue structural lipid profiles through on-line chemical analysis of electrosurgical aerosol toward real-time margin assessment.
\end{abstract}

Methods: Electrosurgical aerosol produced from ex-vivo and in-vivo breast samples was aspirated into a mass spectrometer (MS) using a monopolar hand-piece. Tissue identification results obtained by multivariate statistical analysis of MS data were validated by histopathology. Ex-vivo classification models were constructed from a mass spectral database of normal and tumour breast samples. Univariate and tandem MS analysis of significant peaks was conducted to identify biochemical differences between normal and cancerous tissues. An ex-vivo classification model was used in combination with bespoke recognition software, as an intelligent knife (iKnife), to predict the diagnosis for an ex-vivo validation set. Intraoperative REIMS data were acquired during breast surgery and time-synchronized to operative videos.

Results: A classification model using histologically validated spectral data acquired from 932 sampling points in normal tissue and 226 in tumour tissue provided 93.4\% sensitivity and 94.9\% specificity. Tandem MS identified 63 phospholipids and 6 triglyceride species responsible for 24 spectral differences between tissue types. iKnife recognition accuracy with 260 newly acquired fresh and frozen breast tissue specimens (normal $n=161$, tumour $n=99$ ) provided sensitivity of $90.9 \%$ and specificity of $98.8 \%$. The ex-vivo and intra-operative method produced visually comparable high intensity spectra. iKnife interpretation of intra-operative electrosurgical vapours, including data acquisition and analysis was possible within a mean of 1.80 seconds ( $S D \pm 0.40$ ).

(Continued on next page)

\footnotetext{
* Correspondence: z.takats@imperial.ac.uk; d.leff@imperial.ac.uk

${ }^{\dagger}$ Equal contributors

2Division of Computational and Systems Medicine, Imperial College, London, UK

'Department of BioSurgery and Surgical Technology, Imperial College

London, London, UK

Full list of author information is available at the end of the article
} 
(Continued from previous page)

Conclusions: The REIMS method has been optimised for real-time iKnife analysis of heterogeneous breast tissues based on subtle changes in lipid metabolism, and the results suggest spectral analysis is both accurate and rapid. Proof-of-concept data demonstrate the iKnife method is capable of online intraoperative data collection and analysis. Further validation studies are required to determine the accuracy of intra-operative REIMS for oncological margin assessment.

Keywords: Breast, Cancer, Margins, Intraoperative margin assessment, Surgery, Mass spectrometry, Rapid evaporative ionisation mass spectrometry, REIMS, Intelligent knife, iKnife

\section{Background}

Breast cancer is the commonest cancer in women, with the fifth highest mortality rates worldwide [1]. Breast conserving surgery (BCS) is the most commonly performed surgical technique for the treatment of women with early stage breast cancer in both the United States of America (USA) and the United Kingdom (UK) [2, 3]. On both sides of the Atlantic, over a fifth of patients undergoing BCS require re-operation for inadequate margins [3-7]. Meta-analytical data suggest that a positive resection margin following BCS more than doubles the chance of ipsilateral breast tumour regional recurrence (IBTR) [8]. The risk of relapse is not eliminated by the use of radiotherapy, systemic chemotherapy or endocrine therapy [9].

Re-operation is associated with physical and psychological morbidity and has economic implications. Reoperative intervention is associated with greater patient anxiety, impaired cosmesis [10] and a higher incidence of post-operative wound complications [11], and may delay receipt of adjuvant therapies [12]. Moreover, reoperation increases healthcare costs. For example, an economic model of re-excision of breast margins in the USA predicted that in comparison to positive margins, re-excision of close margins $(<2 \mathrm{~mm})$ accounts for an additional US\$18.8 million per year whilst eliminating re-excision of margins ultimately found to be negative would save a further US\$16.4 million per year [13].

Intraoperative margin assessment (IMA) techniques aim to provide the surgeon with actionable information about margin status in the midst of the index procedure to reduce the need for re-operation. Pathological techniques, frozen section and cytology (i.e. imprint, touch and scrape) are demonstrably accurate [14] and may reduce re-operation rates for positive margins $[15,16]$. For example, frozen section has been demonstrated to significantly reduce reoperation rates from $13.2 \%$ to $3.6 \%$ [17] and its uptake may be cost-effective [18]. However, the limitations of pathological techniques, including slow turnaround times, manpower requirements, and the potential for false positive interpretation, have limited international adoption. Specimen radiology (SR) and intraoperative ultrasound (IOUS) can be used to assess margin status and can be performed within the operating theatre providing direct feedback to the surgeon without the need for specially trained personnel $[19,20]$. However, compared to pathological techniques they have inferior accuracy [14], and hence do not parallel the observed reductions in re-operation rates [21].

Due to the limitations of contemporary IMA techniques a plethora of innovative devices are under development aiming to provide a tool that limits workflow disruption, provides rapid results, optimizes margincontrol and reduces re-operation rates. A variety of imaging and probe-based devices are emerging that are designed to detect differences in tissue properties between cancerous and normal breast tissue [22]. Bioimpedance is the measure of the response of tissue to an externally applied electrical current; the MarginProbe ${ }^{\mathrm{Tm}}$ is quick ( 5-7 minutes) and a 50\% reduction in reoperation rates is achievable despite modest sensitivity and specificity $(\sim 70 \%)[23,24]$. Similarly, the ClearEdge ${ }^{\text {тм }}$ system measures tissue-specific electrical properties with promising preliminary data (sensitivity $\sim 85 \%$, specificity $\sim 80 \%$ ) [25]. Optical spectroscopy techniques such as diffuse reflectance [26-28], Raman spectroscopy [29], optical coherence tomography (OCT) [30], spatial frequency domain imaging [31], fluorescence techniques [32] and confocal microscopy [33] all measure tissue response to light at various wavelengths, and whilst preliminary results are promising [34], the diagnostic accuracy of the techniques is inferior to pathological margin assessment and technological developments are required to increase image processing time and improve the ease of use.

Mass spectrometry (MS) is an innovative addition to the field of margin detection technologies. Molecules are analysed by measuring the mass-to-charge ratio $(\mathrm{m} / \mathrm{z})$ of molecular ions and their charged fragments. MS is wellestablished as a tool for quantifying small molecules and is also valuable for identifying metabolites and biomarkers $[35,36]$. Over the last decade, advances in MS instrumentation have resulted in the ability to detect proteins and metabolites directly from tissues via imaging applications. A variety of MS platforms including matrix-assisted laser desorption/ionisation (MALDI) 
[37] and desorption electrospray ionisation (DESI) [38] show promise in differentiating tissue types with potential applications in rapid tissue diagnostics [39].

Rapid evaporative ionisation mass spectrometry (REIMS) [40-42] is an ambient ionisation technique that utilizes the aerosol by-product of electrosurgical (Bovie) tools. The electrosurgical process of cutting (i.e. continuous radiofrequency (RF) wave) or coagulating (i.e. pulsed RF wave) tissue causes heat to dissipate inside the tissue resulting in cellular explosion and release of cellular content to the gas phase. Aspiration of the aerosol allows for rapid mass spectrometric chemical analysis and computational algorithms can "learn" (cf. 'machine-learning') to recognise the chemical differences between tissue types. The technology can identify tissue characteristics within a few seconds of electrosurgical activation [41].

There is clearly a need to develop a reliable, effective, and rapid IMA method for neoplastic tissue characterization with accuracy competitive with standard histological assessment that can guide resection in vivo and that improves quality in breast surgical oncology. The REIMS system or intelligent knife (iKnife), capable of providing intuitive feedback on real-time tissue characterisation at the point of dissection, offers a potential solution. Here, we test the hypothesis that malignant breast tissues exhibit different metabolic profiles compared to normal breast tissues, and that these changes can be exploited using REIMS. Finally, we demonstrate proof of concept that the iKnife method is capable of intraoperative analysis of electrosurgical vapours.

\section{Methods}

A single-centre, prospective observational study was performed at Imperial College Healthcare NHS Trust (London, UK). Ethical approval was gained from South East London Research Ethics Committee Reference 11/LO/0686, the East of England - Cambridge East Research Ethics Committee Reference 14/EE/0024 and the project was registered under the Imperial College Tissue Bank. Patients ( $>18$ years of age) undergoing breast surgery for benign and malignant disease were recruited. Data were only obtained on patients who had consented to utilization of tissue for research.

Demographic and clinicopathological details included age, operation type, neoadjuvant treatment, post-operative histopathological data including grade (1-3), tumour histological subtype (invasive ductal carcinoma (IDC), invasive lobular carcinoma (ILC), invasive mucinous carcinoma (IMC) or ductal carcinoma in situ (DCIS)), oestrogen receptor (ER) and progesterone receptor (PR) status and human epidermal growth factor receptor 2 (HER2) status (Additional file 1: Table S1). Tumours had to be of a macroscopic size $\geq 2 \mathrm{~cm}$ to allow for adequate research tissue without compromising the clinical diagnosis. Where feasible, tissue was provided from the centre of the tumour from non-necrotic areas. Normal tissue was obtained from patients without malignancy or at a site distant from the tumour specimen. Mass-forming DCIS was suitable for inclusion; however, patients with non-mass-forming DCIS were excluded because the provision of tissue risked compromising the diagnosis.

\section{MS instrument and ex-vivo analysis workflow}

Breast tissue samples were trimmed to size $\left(3-10 \mathrm{~mm}^{2}\right)$ and between 1 and 10 small cuts were made through the tissue using a modified monopolar blade electrosurgical pencil (Medres, Hungary) in either the pure cut setting (continuous RF wave) or fulgurate coag (pulsed RF wave) setting with a ForceTriad ${ }^{\mathrm{m}}$ generator (Medtronic, Ireland). The power setting of the device varied between 10 and $30 \mathrm{~W}$ depending on the size and type of tissue. Aerosol produced as a result of electrosurgical activation was aspirated via the electrosurgical hand-piece [41] and transferred through a plastic tube to the mass spectrometer using a Venturi air jet pump. Surgical aerosol was co-aspirated with propan-2-ol (Sigma, MO, USA) $(0.2 \mathrm{ml} /$ minute) into the vacuum system of the Xevo G2-XS quadrupole time-offlight mass spectrometer (product use is investigational) (Waters, UK). Aerosol particles and solvent droplets were de-clustered using a heated jet disruptor surface in the coarse vacuum regime of the instrument. Gaseous negative ions then entered the MS ion optics and were subjected to mass analysis. The remaining tissue was transferred to histology cassettes and sent to the pathology laboratory to be formalin fixed, paraffin embedded, sectioned and stained with haematoxylin and eosin (H\&E). Subsequently, H\&E-stained slides were examined by senior histopathologists to identify the tissue surrounding the sampling point and assign a tissue diagnosis (i.e. $\mathrm{B} 1=$ normal, $\mathrm{B} 2=$ benign, $\mathrm{B} 3=$ benign with uncertain malignant potential, $\mathrm{B} 4=$ suspicious, $\mathrm{B} 5 \mathrm{a}=\mathrm{in}$ situ, or B5b = invasive tumour) according to the UK Royal College of Pathologists guidelines for non-operative diagnostic procedures and reporting [43].

\section{Construction of the histologically assigned spectral database: spectral processing, bioinformatics and statistical analysis}

To ensure only samples with adequate spectra and representative of true pathological change were used to build the tissue-type MS database, strict inclusion and exclusion criteria were determined (detailed in Additional file 2: Table S2); 40 specimen data files were excluded from a total of 399, leaving 359 for analysis of normal (B1 and B2) versus tumour (B5a and B5b). Raw mass spectrometric data were processed with Offline Model Builder (OMB-v29, Waters Research Centre, Hungary) with a bin of $0.01 \mathrm{~m} / z$ with background subtraction and lock mass correction $(699.497 \mathrm{~m} / z)$. Spectra acquired from 
all sample burns were averaged to produce a single mass spectrum per sample. The mass spectra from all samples were imported into Matlab 2014a (Mathworks, MA, USA) and profile mode alignment [44] was applied prior to peak picking. The data were median fold change normalised and $\log$ transformed prior to multivariate statistical analysis. Principal component analysis (PCA) was used to identify trends in the data. Linear discriminant analysis (LDA) was used to identify spectral differences between cancer and normal tissue. Classification performance was recorded for each model with a leave-one-patient-out cross-validation scheme.

\section{Lipid phenotyping of normal and cancerous human breast tissue with REIMS}

A sub-set of high-density (90-100\%) cancer samples $(n=17)$ was compared to randomly selected normal breast tissue $(n=17)$ to determine the differences in peak intensities between cancerous and normal tissue. Total intensity normalization was performed prior to univariate analysis. The Mann-Whitney $U$ test was performed, with BenjaminiHochburg-Yekutieli false discovery rate correction accounting for multiple testing $(p<0.05)$. Isotope peaks were excluded. Thawed frozen normal $(n=2)$ and cancerous $(n=2)$ breast tissues were sampled in cut mode for 10 15 seconds to allow fragmentation of ions and collection of tandem MS (MS/MS) data. Tentative ion identification was performed by searching peak $m / z$ values in the METLIN metabolite database and with LIPID $\mathrm{MAPS}^{\circ}$ online tools $[45,46]$, which was refined using the MS/MS data.

\section{Ex-vivo iKnife validation}

The accuracy of the combined cut and coag ex-vivo model was tested by exporting the OMB statistical model data into purpose-built OMB recognition software (V29, Waters Research Centre, Hungary). The following parameters were set: mass range 600-1000 $\mathrm{m} / \mathrm{z}, 0.1$ bin, background subtraction on and lock mass correction to $699.497 \mathrm{~m} / z$ (phosphatidic acid (PA) (36:2)). REIMS analysis was performed in cut and coag modalities on new fresh and defrosted, normal and tumour breast tissues with both macro and microscopic histological agreement of tissue type. The validation spectra were pre-processed as previously described, then transformed to the linear discriminant space and classified to the closest class (i.e. normal or tumour) within the space using Mahalanobis squared distances. Recognition output was compared to histopathological results from $H \& E$ slides of the same tissue sample. For the correct classification of normal tissue, spectra from all sampling points within the specimen must have been registered as "normal" breast. Conversely, for tumour, at least one spectrum detected within a sample must have been considered positive for "tumour". Figure 1a illustrates the ex-vivo recognition workflow. For additional validation, real-time ex-vivo tumour detection was performed on three mastectomy sections using electrosurgical dissection through normal breast into tumour tissue and back to normal breast tissue. The acquisition of REIMS spectra was synchronized with a video recording (GoPro, CA, USA) of the smoke capture as the tissue was
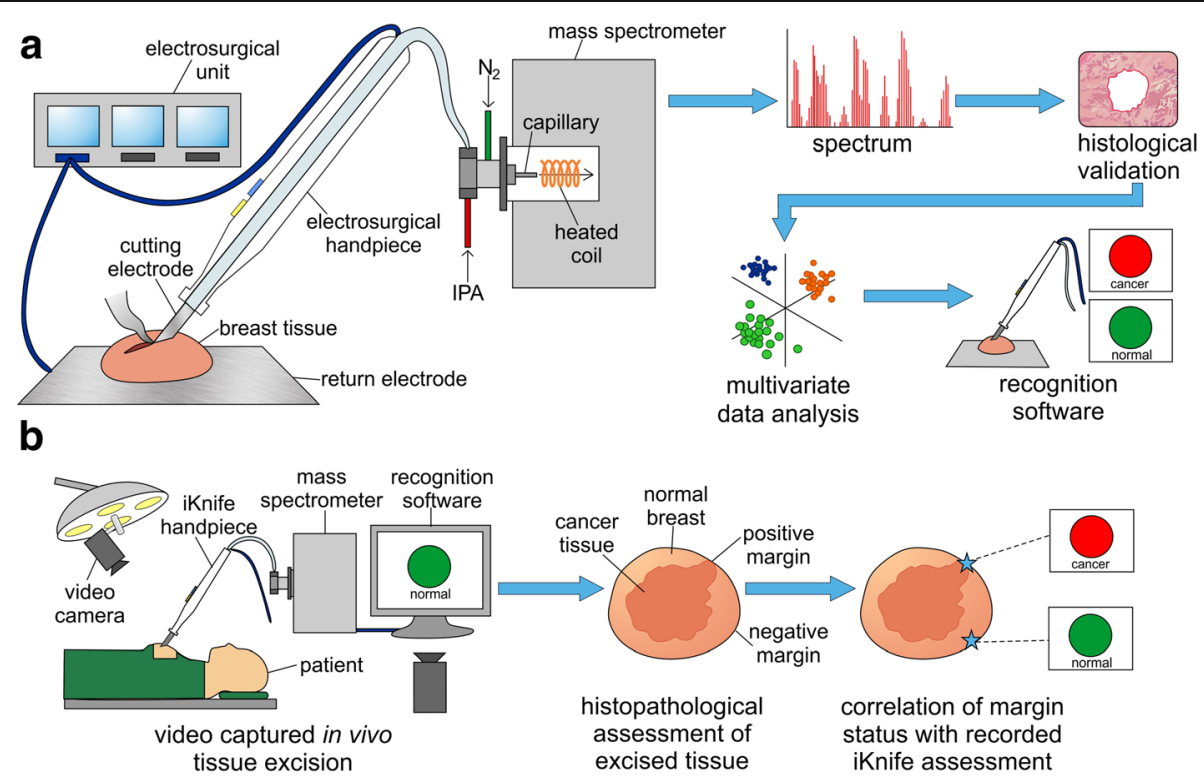

Fig. 1 Ex-vivo and intraoperative workflows. a Ex-vivo workflow from generation of spectra by mass spectrometry (MS) analysis of surgical aerosol through to model building by multivariate statistics leading to ex-vivo recognition of tissue in real time. $\mathbf{b}$ Intraoperative workflow from generation of spectra in real time by on-line MS analysis, through to determination of margin status by histopathological assessment and correlation to iKnife results 
continuously cut or coagulated with an electrosurgical blade. OMB recognition software was used to classify tissue content and this was compared to macroscopic tissue observations.

\section{Intraoperative iKnife - proof of principle}

To determine if the ex-vivo method was applicable to the intraoperative environment we ran an intraoperative proof-of-principle study. A modified Xevo G2-XS mass spectrometer (Waters, UK) was installed in the operating theatre and a commercially available sterile (Surg-N-Vac or AccuVac, Covidien, UK) hand-piece was connected to the instrument. Aerosol produced as a result of electrosurgical tissue manipulation was continuously aspirated into the instrument throughout the operation. Video footage was simultaneously recorded, capturing all activities occurring at the operative scene (GoPro, CA, USA) in a time-synchronized manner with the acquisition of spectral data. Video recordings enabled retrospective orientation of spectral data with regard to three-dimensional margins. However, presently sample size is inadequate for interpretation of diagnostic accuracy. An optimised iKnife intraoperative workflow is displayed in Fig. 1 b.

\section{Results}

REIMS spectral differences between tissue type and electrosurgical modality

Average spectra obtained from 253 normal (B1 and B2) and 106 tumour (B5a and B5b) samples were used to create typical REIMS multispectral "fingerprints" for normal and cancerous breast tissue in both cut and coag electrosurgical modalities (Fig. 2). Spectral feature intensities were significantly dependent on the tissue type and electrosurgical setting used. Normal tissue demonstrated high intensity spectra in the phospholipid range $(600-850 \mathrm{~m} / \mathrm{z})$ and the triglyceride range $(850-1000 \mathrm{~m} / \mathrm{z})$ using cut mode

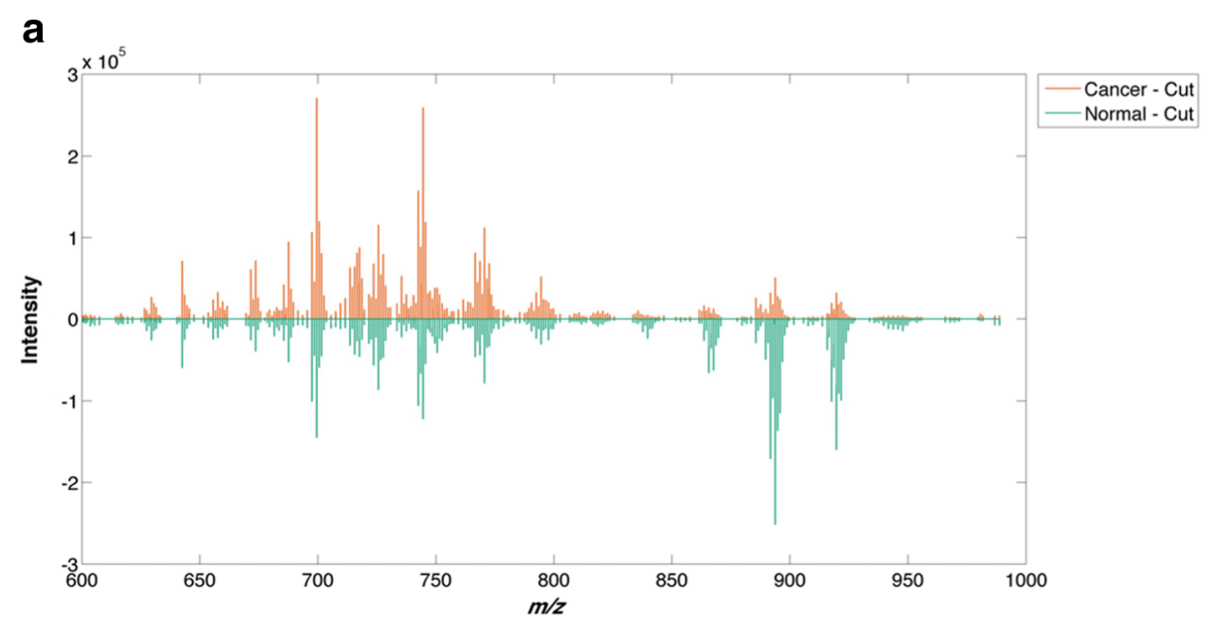

b

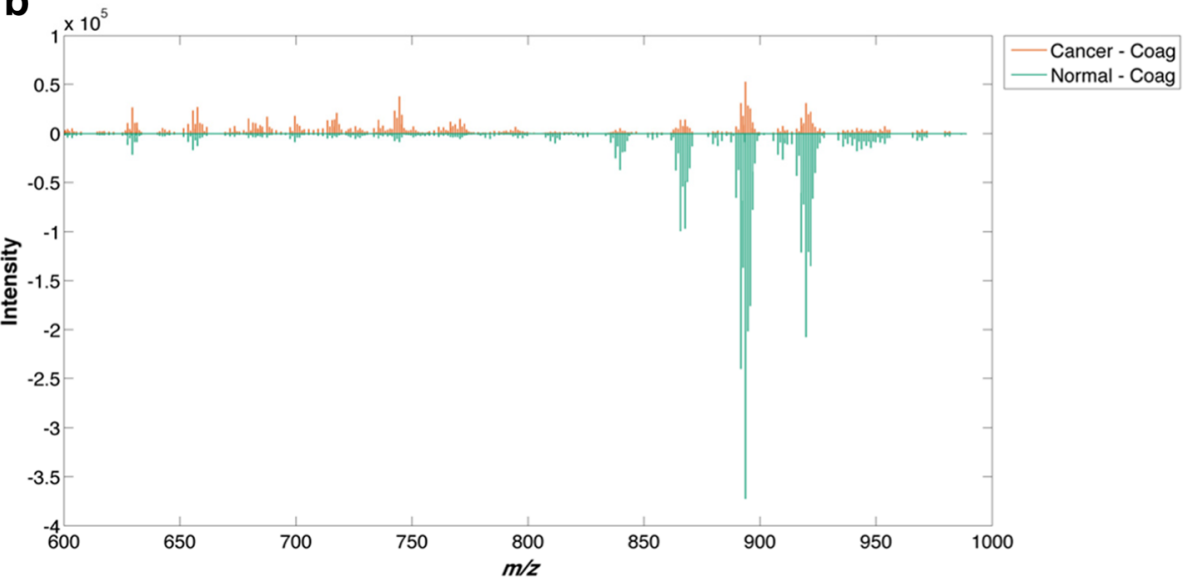

Fig. 2 Mean spectral intensity for cancer and normal tissues during cutting (cut) and coagulation (coag) electrosurgical modalities. The $\mathrm{m} / \mathrm{z}$ intensities are positive for both normal and tumour; here positive intensities are reflected opposite each other to illustrate similarities and differences between the groups. The intensity of triglycerides $(850-1000 \mathrm{~m} / \mathrm{z})$ is greater than the intensity of phospholipids $(600-850 \mathrm{~m} / \mathrm{z})$ in normal breast tissue $(\mathbf{a}, \mathbf{b})$, whilst the membrane phospholipids are more dominant in breast cancer $(\mathbf{a}, \mathbf{b})$. Differences are observed between cut mode (a) and coag mode (b). Coag mode, compared to cut mode, gives a higher triglyceride signal but lower phospholipid signal 
and predominantly in the triglyceride range using coag mode. Conversely, tumour tissue demonstrated an increase in the phospholipid range and a decrease in the triglyceride range in both cut and coag modalities.

\section{Creation of a REIMS ex-vivo breast tissue classification model}

Statistical models were created for normal breast (B1 and $\mathrm{B} 2$ ) versus breast tumour (B5a and B5b) using cut, coag or a combination of the two (combined model). Data from 1158 sampling points from a total of 359 individual specimens; 253 normal (932 sampling points) and 106 tumour specimens (226 sampling points) from 113 patients were used to build the combined model (Table 1). The combined model was selected for recognition as both cut and coag modalities are frequently used interchangeably during breast cancer surgery. For the combined model, tumour class was distributed as 42 IDC, 8 ILC, 4 IMC and 2 DCIS (Table 1 and Additional file 1: Table S1). The mean ( \pm standard deviation (SD)) age of patients in the combined group was 57.2 years $( \pm 13.48)$. The leave-one-patient-out cross-validation of the corresponding statistical model based on individual specimens $(n=359)$ resulted in overall accuracy of $94.4 \%$, sensitivity of $93.4 \%$ and specificity of $94.9 \%$ (Fig. 3). For completeness, the cut model resulted in accuracy of $95.8 \%$, sensitivity of $94.7 \%$ and specificity of $96.2 \%$ (Additional file 3: Figure S1), whilst the coag model resulted in overall accuracy of $94.7 \%$, sensitivity of $93.9 \%$ and specificity of 95.0\% (Additional file 4: Figure S2).

\section{Identification of lipids in significant peaks by MS/MS}

Univariate statistical analysis was used to identify significant peaks that differed between normal and cancerous tissue. After exclusion of isotopes, 24 significant peaks remained; 18 were higher in tumour tissue, with an average of $0.5 \log _{2}$ fold increase compared to normal and 6 peaks were lower in tumour, with an average of $5.7 \log _{2}$ fold decrease (Fig. 4 and Additional file 5: Table S3). The five most significant variables with

Table 1 Ex-vivo database model statistics and demographics

\begin{tabular}{|c|c|c|c|c|}
\hline & & Cut & Coag & Cut and coag combined \\
\hline \multirow[t]{3}{*}{$\overline{\text { Total }}$} & Sampling points & 634 & 524 & 1158 \\
\hline & Samples & 190 & 169 & 359 \\
\hline & Patients & 108 & 105 & 113 \\
\hline \multirow[t]{3}{*}{ Normal (B1 and B2) } & Sampling points & 510 & 422 & 932 \\
\hline & Samples & 133 & 120 & 253 \\
\hline & Patients & 95 & 93 & 103 \\
\hline \multirow[t]{3}{*}{ Tumour (B5a and B5b) } & Sampling points & 124 & 102 & 226 \\
\hline & Samples & 57 & 49 & 106 \\
\hline & Patients & 53 & 46 & 56 \\
\hline \multirow[t]{4}{*}{ Tumour type } & IDC & 39 & 33 & 42 \\
\hline & ILC & 8 & 7 & 8 \\
\hline & IMC & 4 & 4 & 4 \\
\hline & DCIS & 2 & 2 & 2 \\
\hline \multirow[t]{5}{*}{ Tumour receptor status } & ER+/HER2-negative & 42 & 37 & 45 \\
\hline & ER+/HER2-positive & 3 & 3 & 3 \\
\hline & ER-/HER2-positive & 3 & 2 & 3 \\
\hline & Triple-negative & 3 & 2 & 3 \\
\hline & DCIS & 2 & 2 & 2 \\
\hline \multirow[t]{3}{*}{ Age (mean) } & All & 57.56 & 57.16 & 57.15 \\
\hline & Normal & 57.14 & 56.63 & 56.51 \\
\hline & Tumour & 60.94 & 62.13 & 60.73 \\
\hline \multirow[t]{3}{*}{ Model statistics } & Sensitivity & $94.7 \%$ & $93.9 \%$ & $93.4 \%$ \\
\hline & Specificity & $96.2 \%$ & $95.0 \%$ & $94.9 \%$ \\
\hline & Accuracy & $95.8 \%$ & $94.7 \%$ & $94.4 \%$ \\
\hline
\end{tabular}

Statistics and demographics displayed for three ex-vivo models (Cut, Coag and Combined). IDC invasive ductal carcinoma, ILC invasive lobular carcinoma, IMC invasive mucinous carcinoma, DCIS ductal carcinoma in situ, ER+ oestrogen receptor positive, $E R$ - oestrogen receptor negative, $H E R 2+$ human epidermal growth factor receptor 2 positive, HER- human epidermal growth factor receptor 2 negative 


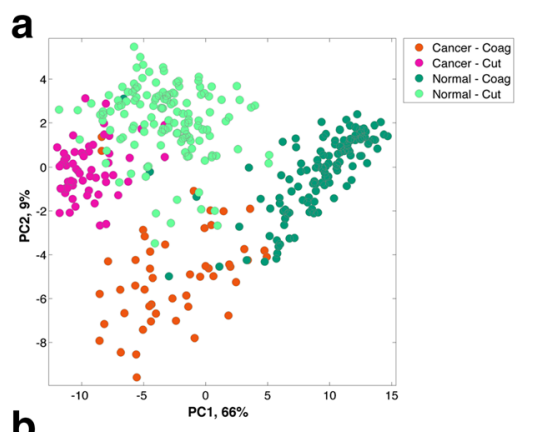

C
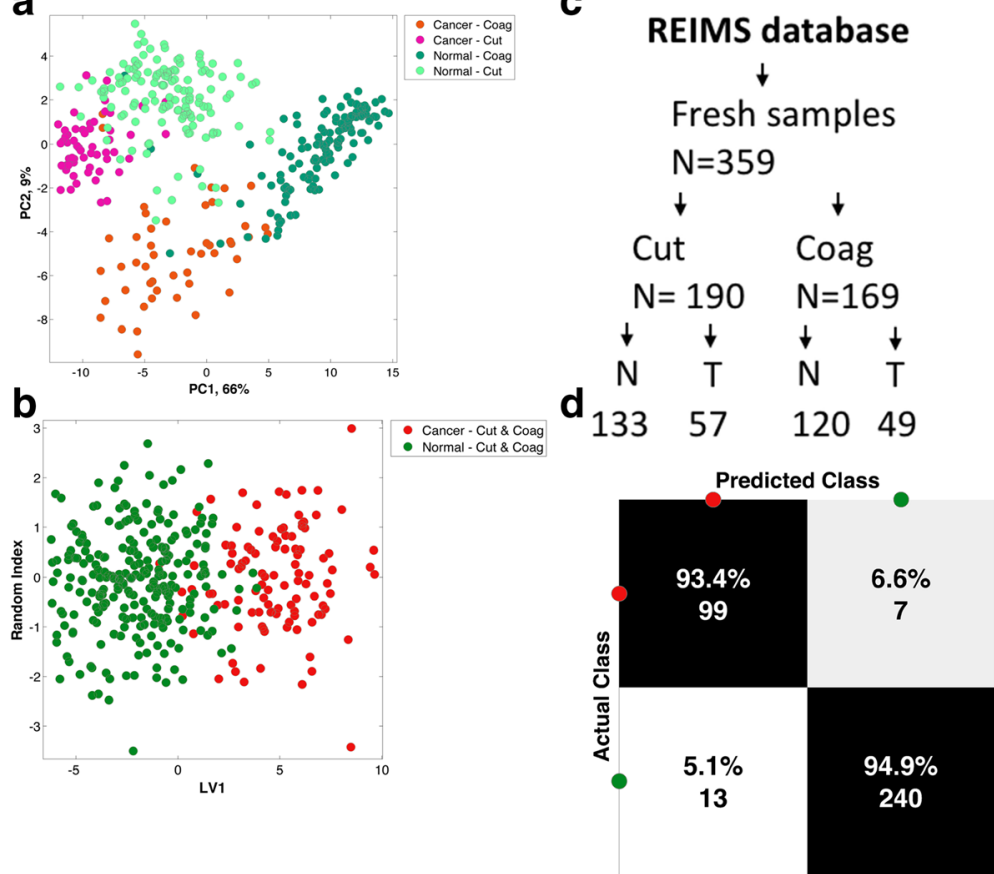

Fig. 3 Multivariate statistical analysis of the combined cut and coag model. a Unsupervised principal component ( $P C$ analysis of the spectral differences (600-1000 m/z) between normal tissue compared to breast cancer in the cut and coag electrosurgical modalities. b Supervised linear discriminant analysis plot comparing normal tissue $(N)$ to tumour/cancer $(T)$ regardless of electrosurgical modality. $\mathbf{c}$ Flow diagram of sample selection for building of the rapid evaporative ionisation mass spectrometry (REIMS) database. $\mathbf{d}$ Confusion matrix demonstrating diagnostic accuracy of the combined electrosurgical model following leave-one-patient-out cross-validation (LV1), with sensitivity (93.4\%) and specificity (94.9\%)

higher cancer intensity are plotted in Fig. $5 \mathrm{a}$, and the five variables with higher intensity in normal samples are plotted in Fig. 5b. MS/MS experiments were performed to identify the lipid species. Table 2 highlights the phospholipid species identified from the MS/MS spectra that were elevated in cancer compared to normal tissue $(600-850 \mathrm{~m} / \mathrm{z}$ range). All of the lipids identified in this range were glycerophospholipids with phosphatidylethanolamines (PEs) being the most commonly identified lipid species, followed by phosphatidylcholines (PCs), phosphatidic acids (PAs), phosphatidylserines (PSs) and phosphatidylglycerols (PGs) in that order. Table 3

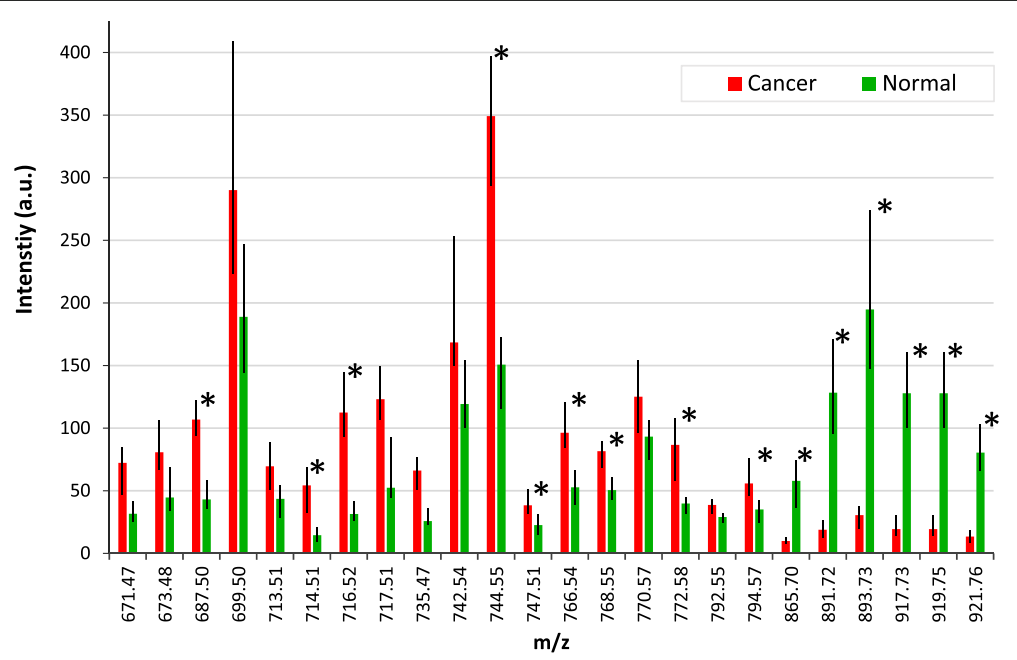

Fig. 4 Graph shows statistically significant differences $(p<0.05)$ in the mean intensity of the $\mathrm{m} / \mathrm{z}$ peaks in normal tissue and in cancer $\left({ }^{*}=q\right.$ value (false discovery rate (FDR)-corrected $p$ value) $\leq 0.001$ ). Range bars represent the interquartile range. There were 18 peaks that increased in cancer within the phospholipid range $(600-850 \mathrm{~m} / \mathrm{z}) ; 6$ peaks increased in normal tissue within the triglyceride range $(850-1000 \mathrm{~m} / \mathrm{z})$. a.u. arbitrary units 


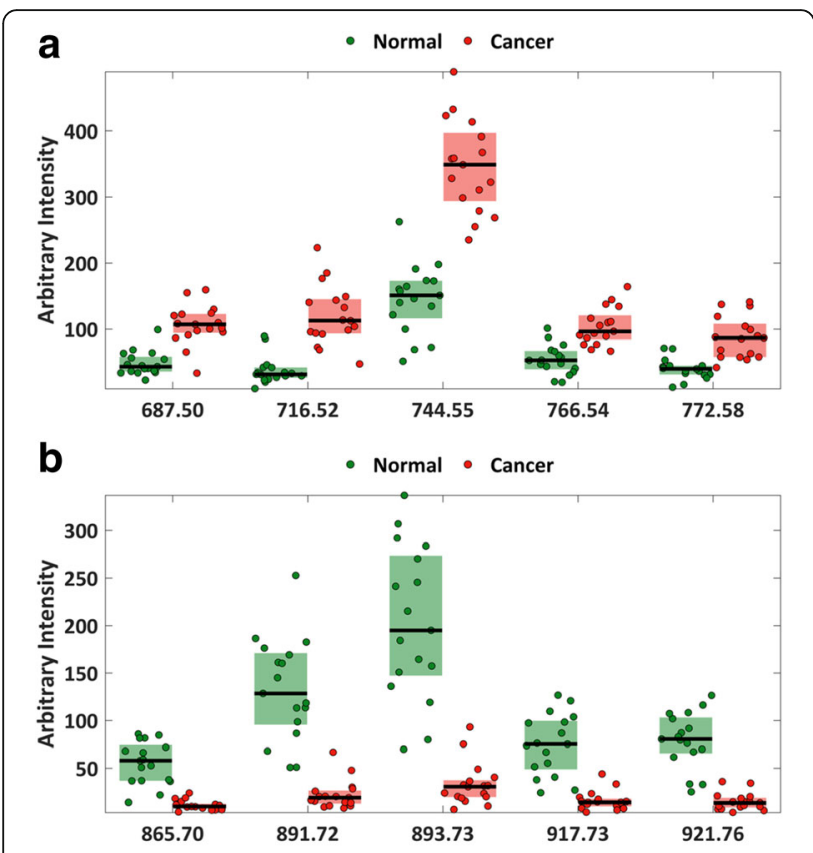

Fig. 5 Intensities of five significant features that had higher intensities in cancer samples (a) and five significant features that had higher intensities in normal samples (b). The features are the most significant ones identified by univariate analysis (see Fig. 4 and Additional file 5: Table S3). The bottom and top of the coloured band represent, respectively, the 25th and 75th percentiles of the group, with the median denoted by the black line. The individual intensities for each group have been scattered with a random amount of $x$-axis positional variation

summarises the triglyceride species identified from the MS/ MS spectra of peaks that were significantly lower in cancer $(850-1000 \mathrm{~m} / z)$.

\section{Ex-vivo validation of iKnife}

New frozen and fresh breast specimens $(n=260)$ not previously used for ex-vivo model creation were subjected to iKnife analysis using both cut and coag modalities, employing an identical ex-vivo methodology combined with interpretation by bespoke iKnife recognition software (OMB V29). For the cut modality there were 79 normal and 48 tumour specimens and for the coag modality there were 82 normal and 51 tumour samples. Recognition software was concordant with final histopathological assessment in 249 out of 260 specimens, producing an overall model accuracy of $95.8 \%$ with a sensitivity of $90.9 \%$ and specificity of $98.8 \%$ (Fig. 6). Finally, the iKnife was used to perform a continuous dissection line through the tissue in cut and coag mode from normal, through tumour returning to normal tissue, in a case series of three whole mastectomy slices with large tumours $(>3 \mathrm{~cm})$. OMB recognition results demonstrated good overall classification (224/231 spectra, $97 \%$ accuracy) with video synchronised macroscopic tissue correlation (Fig. 7).

\section{Intraoperative iKnife - proof of principle}

The iKnife was used during the entire surgical intervention in six case studies as a proof of principle of the intraoperative method. The mean time from electrosurgical activation to detection of online analysis was $1.80 \mathrm{sec}-$ onds ( $\mathrm{SD} \pm 0.40)$. High intensity spectra (total ion count $(\mathrm{TIC})=\mathrm{e} 7-\mathrm{e} 8)$ were obtained in all surgical interventions both in cut and coag mode throughout the operation and were comparable in intensity (TIC = e6-e8) and overall visual morphology to the ex-vivo spectra (Fig. 8). Of the intraoperative spectra across six surgical interventions, 99.27\% $(n=5422 / 5462)$ were interpretable by the ex-vivo model. Only $0.73 \%(n=40 / 5462)$ of spectra were classified as outliers (greater than 2 SD) according to the ex-vivo classification model.

\section{Discussion}

A REIMS-based histological identification method has been successfully optimised for the real-time analysis of heterogeneous breast tissues. The construction of an exvivo database from fresh breast tissues demonstrated significant differences in spectra related to disparity in lipid metabolism between normal breast tissues and breast cancer. Spectral differences observed between $c u t$ and coag electrosurgical modalities have been combined to create a multivariate statistical model allowing the use of both modes interchangeably. Leave-one-patient-out cross-validation demonstrates this model can detect tumour with a sensitivity of $94.9 \%$ and exclude tumour with a specificity of $93.4 \%$, results that rival other IMA techniques [34].

MS/MS has been used to characterise key lipid species present in normal and cancerous breast tissue. Abundance of ions associated with phospholipid species $(600-850 \mathrm{~m} / \mathrm{z})$ were increased in cancer tissues compared to healthy tissue types, whereas intensity of ions associated with triglyceride species $(850-1000 \mathrm{~m} / z)$ were decreased; a finding also reported by using alternative techniques $[47,48]$. Phospholipids serve as chief components of biological membranes and hence they are indispensable for proliferating cells [49]. An increase in phospholipid synthesis is associated with lipogenic enzymes including fatty acid synthase and acetyl-CoA carboxylase a, which are commonly upregulated in breast cancer [50]. Lipid species, PE and PC, identified by REIMS MS/MS have also been identified by other studies to be increased in breast cancer cells [48]. Interestingly, PC (16:0/ 16:0), PC (18:0/20:4), PC (18:1/20:4) have been previously identified to be associated with ER-negative tumours and higher grade tumours, and associated with decreased overall survival in breast cancer patients [50].

Significant advances in software development have enabled real-time analysis of tissue composition and rapid comparison against the multispectral database of 
Table 2 MS/MS-based phospholipid identification increased in breast cancer $(600-850 \mathrm{~m} / \mathrm{z})$

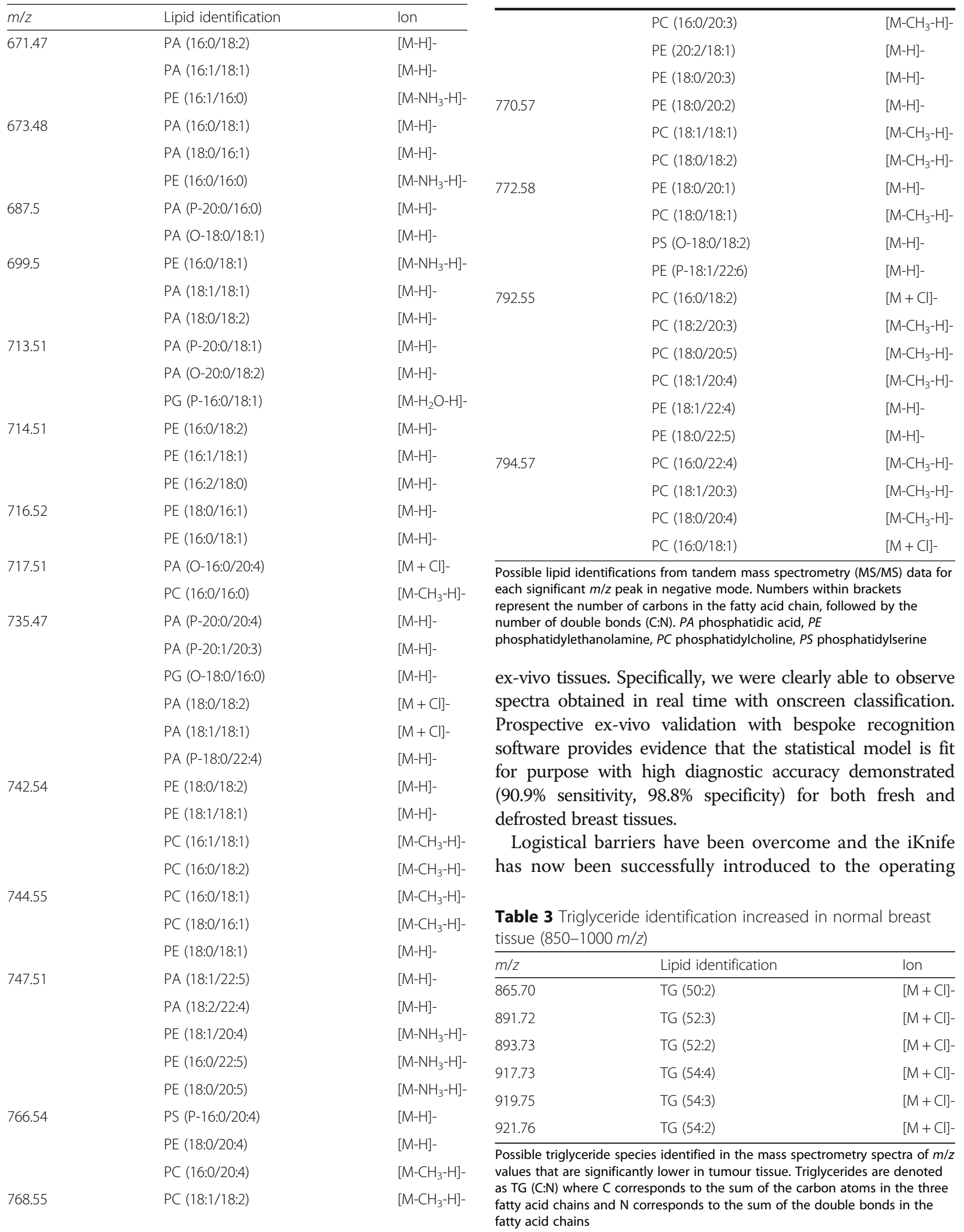

Table 2 MS/MS-based phospholipid identification increased in breast cancer (600-850 m/z) (Continued) 


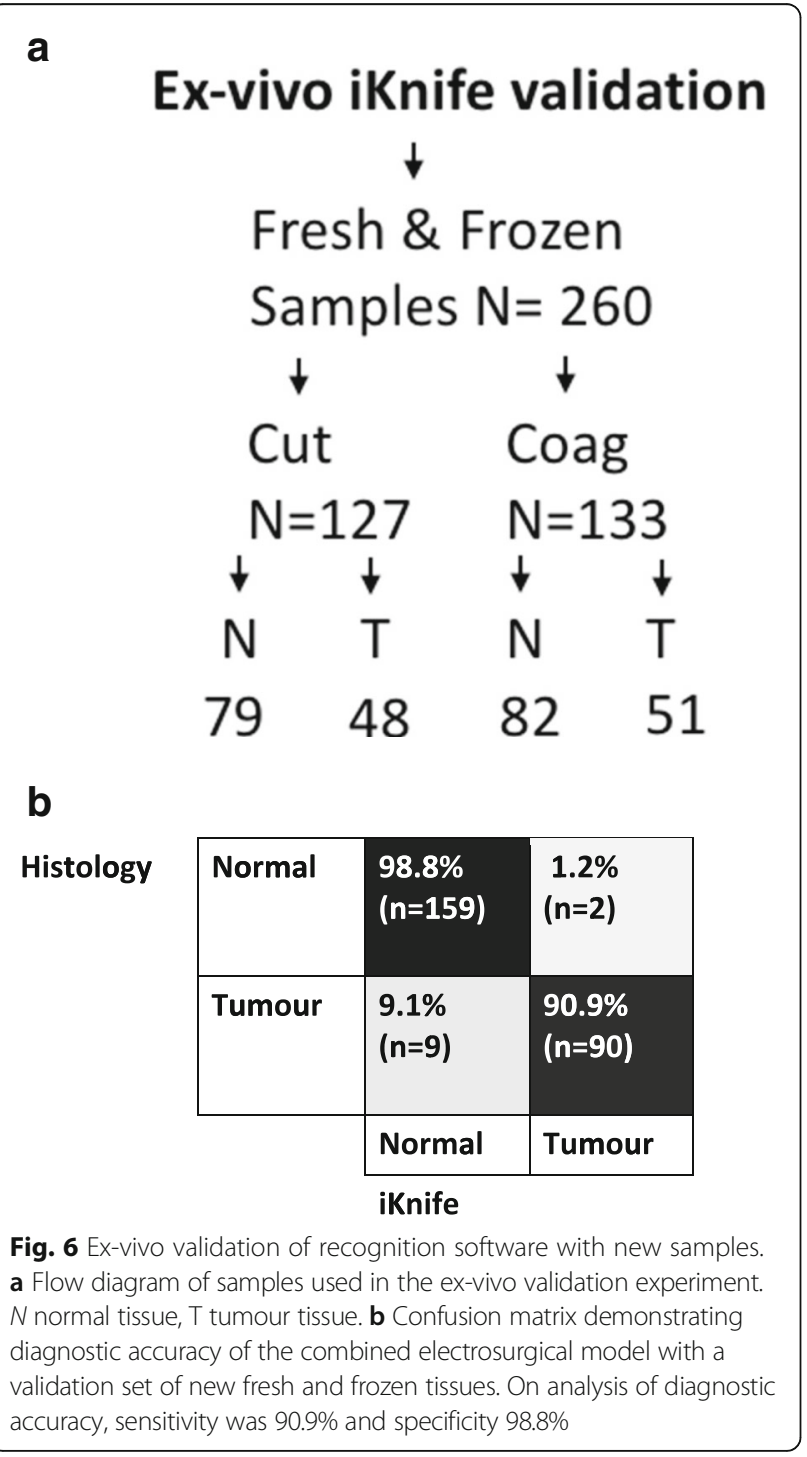

theatre, with a method that has been demonstrated as a proof of concept, to function well during breast surgery. Despite additional factors to consider such as blood flow and body temperature, high intensity mass spectral data were obtained during breast surgery, comparable to data obtained in the ex-vivo setting. An ex-vivo classification model was able to recognize a very high proportion of intraoperative spectra (>99\%), which suggests that ex-vivo models trained on tissue type will be able to guide intraoperative analysis. Analysis of the diathermy smoke plume can be performed throughout the entire operation with results presented on screen within 2 seconds of diathermy activation. Hand-piece modifications could further improve the speed of results. Increased intraoperative numbers and appropriate translation of the ex-vivo recognition software for intra-operative use is required before conclusions can be made on the intraoperative diagnostic accuracy, and this remains the focus of our ongoing work.
The definition of what constitutes a positive margin continues to be debated; however, recent guidelines from the USA point to a narrowing of the accepted positive margin distance. The Society of Surgical Oncology and American Society for Radiation Oncology (SSO-ASTRO) advises that in invasive disease a negative margin should be considered as "no tumour on ink" [51]. This is based on the results from a meta-analysis that demonstrated an increase of 2.44 in the odds ratio of local recurrence for positive margins (tumour on ink) but with no significant benefits demonstrated for wider margins [8]. Interestingly, only relatively small further reductions in re-operation rates from $20.2 \%$ to $16.5 \%$ [52] and from $21.4 \%$ to $15.1 \%$ [53] have been observed following acceptance of the 2014 SSO-ASTRO guidelines and these reduced rates could still be considered excessive. Extrapolation of re-operative rates of $15 \%$ combined with the annual incidence of breast cancer and the increasing popularity of breast conserving surgery, amounts to many thousands of women undergoing potentially unnecessary operations with a significant health and economic cost to the patient and healthcare provider [13]. The fact that re-operation rates of $3.6 \%$ have been demonstrated following breast conserving surgery with the use of routine frozen section margin assessment [17] provides evidence that IMA techniques or technologies with high diagnostic accuracy could be expected to substantially reduce positive margin rates beyond those achieved by a reduction in positive margin width alone. It is therefore our opinion that there continues to be a need for accurate and rapid IMA technology capable of further reducing re-operation rates.

Although there are numerous established and emerging IMA devices, penetration to routine practice has been poor. Pathological techniques require complicated logistics between the operating theatre and pathology departments, sufficiently trained pathologists are a scarce resource and time taken to report results can be long and can delay operative workflow (24-50 minutes) $[54,55]$. Both SR and IOUS guided surgery can be used directly by surgeons within the operating theatre; however neither technique is as accurate as pathological approaches and both are subject to intraobserver error [34]. A common limitation of all emerging technologies such as MarginProbe ${ }^{\text {Txx }}$ [23, 24], ClearEdge ${ }^{\text {тu }}$ [25] or OCT [30] is the need to disrupt workflow demanding an additional probe during resection or specimen analysis following resection. Following excision, the exact orientation of the surgical specimen can prove to be challenging and this may affect accurate margin identification.

As a margin detection and optimisation device, the REIMS-based iKnife has a significant advantage in that there is no disruption to standard oncological workflow 


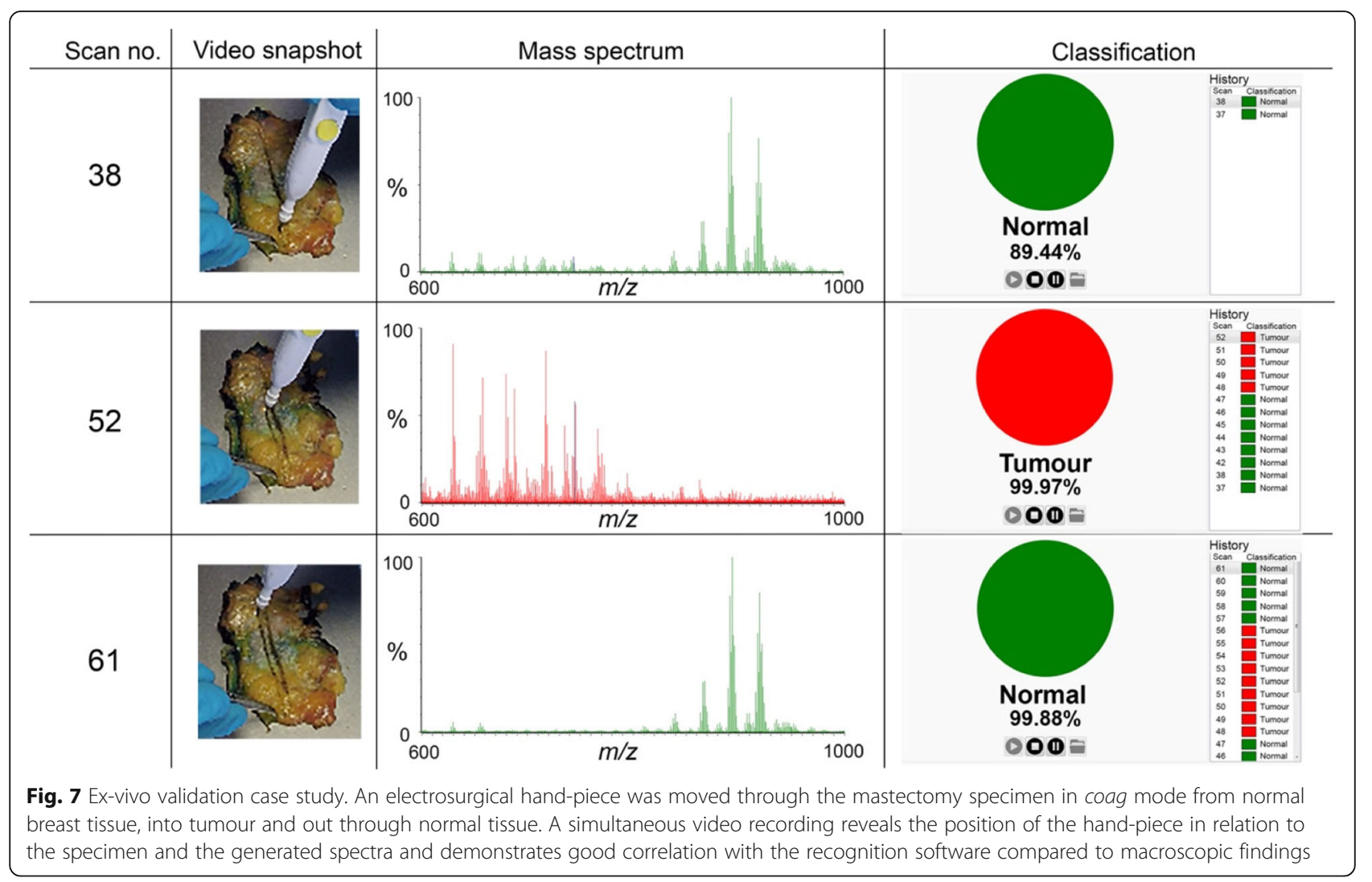

because the margin control device is coupled to the resection tool. Furthermore, results may be obtained fast enough to alter tissue excision in real time and hence may reduce problems with retrospective tissue orientation. Perhaps the most exciting attribute of the iKnife is the ability to compare chemical changes in cellular metabolism with tissue morphology as determined by pathological assessment. The iKnife is envisaged to be more than just an IMA tool and has the potential to provide real time chemical information about individual tumour biology, important in an era of precision medicine as we move towards offering bespoke treatments based on tumour/tissue biology [56].

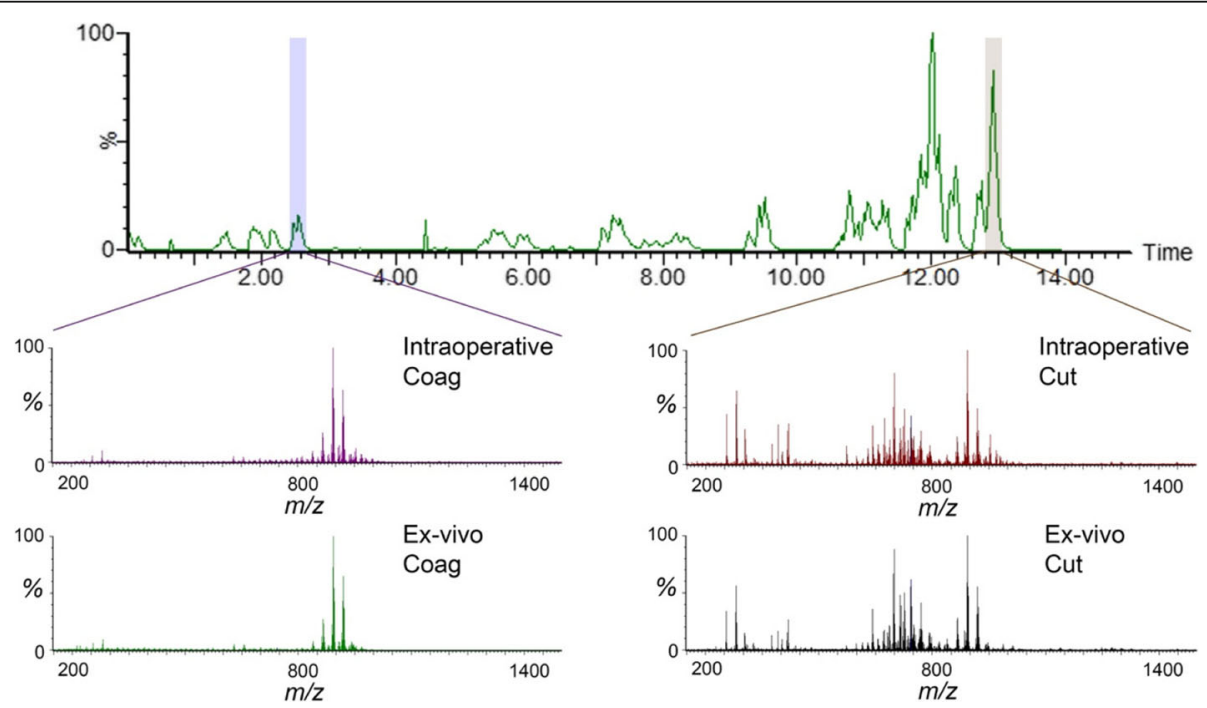

Fig. 8 Collection of intraoperative mass spectral data with comparison to ex-vivo spectra. Spectral intensity over time obtained throughout entire surgery (14 minutes), one spectra obtained per second. Intraoperative spectral differences highlighted in cut (right) and coag (left) modalities observed in normal tissue and compared to similar spectra observed in two ex-vivo examples 


\section{Limitations}

Due to the width of the electrosurgical blade $(4 \mathrm{~mm})$ the iKnife has relatively low resolution that may lead to dilution of tumour cellular content by normal cells, which may provoke a false positive result. REIMS is a destructive process, therefore it is impossible to be certain of the histology of the exact cells under analysis. The need to perform REIMS analysis on tissue prior to formalin fixation and microscopic assessment limited the number of cases of ductal carcinoma in situ (B5a) that were available for inclusion. There is uncertainty about how the iKnife will classify solid benign lesions. In a sub-set analysis of tumour (B5b) versus fibroadenoma (B2) (Additional file 6: Figure S3), good sensitivity (94.1\%) but poorer specificity (87.3\%) was observed, indicating that the spectral differences between these two groups are subtler than comparisons between either of these entities and normal tissue.

\section{Conclusion}

A mass spectrometric method for the rapid analysis of heterogeneous breast tissues has been developed. REIMS analysis can be performed in both the cut and coag modes, which allows the surgeon to alternate between modes as clinically necessary. Preliminary data suggest the iKnife is capable of accurately separating breast tissue types by interpretation of the cellular chemical constituents. Recognition software enables real-time analysis of both ex-vivo and in-vivo breast tissue. The iKnife method has been optimised and further work will focus on determining the accuracy of the tool for intraoperative classification of resection margins.

\section{Additional files}

Additional file 1: Table S1. Ex-vivo database tumour characteristics for samples included in the ex-vivo database. ER oestrogen receptor, $P R$ progesterone receptor, HER2 human epidermal growth factor receptor 2 (DOCX $156 \mathrm{~kb}$ ).

Additional file 2: Table S2. Inclusion and exclusion criteria for construction of the histologically assigned spectral database; 40 specimen files were excluded from a total of 399, leaving 359 specimen files for analysis of normal tissue (B1 and B2) versus tumour (B5a and B5b) (DOCX $44 \mathrm{~kb})$.

Additional file 3: Figure S1. Multivariate statistical analysis of the cut model. a Unsupervised principal component analysis (PCA) analysis of the spectral differences $(600-1000 \mathrm{~m} / \mathrm{z}$ ) between normal tissue compared to breast cancer using the cut electrosurgical modality. b Supervised linear discriminant analysis (LDA) plot comparing normal tissue to tumour using cut mode. c Confusion matrix demonstrating diagnostic accuracy of the cut model, following leave-one-patient-out cross-validation, with sensitivity (94.7\%) and specificity (96.2\%) (DOCX 367 kb).

Additional file 4: Figure S2. Multivariate statistical analysis of the coag model. a Unsupervised PCA analysis of the spectral differences (600-1000 m/z) between normal tissue compared to breast cancer using coag electrosurgical modality. $\mathbf{b}$ Supervised LDA plot comparing normal tissue to tumour using coag mode. c Confusion matrix demonstrating diagnostic accuracy of the coag model following leave-one-patient-out cross-validation, with sensitivity (93.9\%) and specificity (95.0\%) (DOCX 332 kb).

Additional file 5: Table S3. Significant $\mathrm{m} / \mathrm{z}$ peak differences in mean intensity between normal tissue and cancer, with fold changes and $q$ value (false discovery rate (FDR)-corrected $p$ value). Negative fold changes denote peaks that are lower in tumour compared with normal tissue (DOCX $48 \mathrm{~kb}$ ).

Additional file 6: Figure S3. Multivariate statistical analysis of fibroadenoma (B2) compared to cancer (B5b). a Unsupervised PCA analysis of the spectral differences $(600-1000 \mathrm{~m} / \mathrm{z}$ ) between fibroadenoma samples compared to breast cancer using combined cut and coag electrosurgical modalities. b Supervised LDA plot comparing fibroadenoma to cancer using cut and coag modes. c Confusion matrix demonstrating diagnostic accuracy of the model: 55 solid fibroadenoma samples are compared to 101 tumour (B5b) samples. Sensitivity of tumour classification is high at $94.1 \%$ but specificity for the diagnosis of benign fibroadenoma is lower at $87.3 \%$ (DOCX $364 \mathrm{~kb}$ ).

\section{Abbreviations}

BCS: Breast conserving surgery; DCIS: Ductal carcinoma in situ; DESI: Desorption electrospray ionisation; ER: Oestrogen receptor; H\&E: Haematoxylin and eosin; HER2: Human epidermal growth factor receptor 2; IBTR: Ipsilateral breast tumour regional recurrence; IDC: Invasive ductal carcinoma; iKnife: Intelligent knife; ILC: Invasive lobular carcinoma; IMA: Intraoperative margin assessment; IMC: Invasive mucinous carcinoma; IOUS: Intraoperative ultrasound; IPA: Isopropyl alcohol / propan-2-ol; LDA: Linear discriminant analysis; MALDI: Matrix-assisted laser desorption ionisation; MS/MS: Tandem mass spectrometry; MS: Mass spectrometry; OCT: Optical coherence tomography; OMB: Offline model builder; PAs: Phosphatidic acids; PCA: Principal component analysis; PCs: Phosphatidylcholines; PEs: Phosphatidylethanolamines; PGs: Phosphatidylglycerols; PR: Progesterone receptor; PSs: Phosphatidylserines; REIMS: Rapid evaporative ionisation mass spectrometry; RF: Radiofrequency; SD: Standard deviation; SR: Specimen radiology; TG: Triglycerides; TIC: Total ion count; UK: United Kingdom; USA: United States of America

\section{Acknowledgements}

We would like to thank the Imperial College Tissue Bank for their help with sample collection and storage. We thank the histopathology laboratory at Charing Cross for their time, skills and resources. Finally, we thank all those who have helped with the mass spectrometer instrumentation, including Emma White, Adele Savage, Louise Gildea, Hui-Yu Ho, Luisa Doria and Dipa Gurung. This work has been presented, in part, at the: Association of Breast Surgeons annual conference, Belfast, UK. May 2017.

\section{Funding}

This work was supported by project grants from the Association of Breast Surgeons (UK) and Waters Corporation. The research leading to these results has received funding from the European Research Council under the European Union's Seventh Framework Programme (FP7/2007-2013) / ERC grant agreement $n^{\circ}$ 617896. Support was also obtained from the Imperial NIHR Biomedical Research Centre and Imperial Cancer Research UK Centre. Edward St John received a one-year research Fellowship from the Royal College of Surgeons of England.

\section{Availability of data and materials}

The datasets used and/or analysed during the current study are available from the corresponding author on reasonable request.

\section{Authors' contributions}

The motivation and need for the study was conceived and developed by ERS, JB, DRL, AD and ZT. The study design was developed by ERS, JB, DRL and ZT. Ethics approval was co-ordinated by LM. Data collection was performed by ERS, JB, AC and MR. Histopathological diagnosis and support was performed by FR, AS, RR and SS. Biostatistical analysis was conducted by ERS, JB and JSM. Data interpretation was performed by ERS, JSM, JB, and ZB in consultation with DRL, AD and ZT. The manuscript was drafted by ERS, DRL, $J S M, J B, Z B$ and AC. Critical editing of the manuscript was performed by DRL, $\mathrm{ZT}$ and $\mathrm{AD}$. All authors read and approved the final manuscript. 


\section{Authors' information}

Mr Edward St John MBBS, BSC, MRCSeng, is a breast and general surgeon currently completing a PhD whilst working as a Clinical Research Fellow at Imperial College London and Imperial College Healthcare NHS Trust. He was awarded a one-year research fellowship from the Royal College of Surgeons of England. He is also an NHS England Clinical Entrepreneur Fellow. Professor Ara Darzi MD, FRCS, FACS, FMedSci, FRS, holds the Paul Hamlyn Chair of Surgery at Imperial College London, the Royal Marsden Hospital and the Institute of Cancer Research. He is Director of the Institute of Global Health Innovation at Imperial College London and Chair of Imperial College Health Partners. He is an Honorary Consultant Surgeon at Imperial College Healthcare NHS Trust. Professor Zoltan Takats PhD, is a professor of analytical chemistry at Imperial College London. He has pursued pioneering research in mass spectrometry and he is one of the founders of the field of "ambient mass spectrometry". He is the primary inventor of six mass spectrometric ionisation techniques including rapid evaporative ionisation mass spectrometry (REIMS). Mr Daniel Leff MBBS, FRCS, MS, PhD, is a Clinical Senior Lecturer working in the Departments of BioSurgery and Surgical Technology and Hamlyn Centre for Robotic Surgery at Imperial College London. He is an Honorary Consultant in Oncoplastic Breast Surgery working within the Breast Unit at Imperial College Healthcare NHS Trust.

\section{Competing interests}

ZT acts as a consultant for Waters Corporation. AD has chaired a strategic advisory board meeting for Waters Corporation. JB is employed by Waters Corporation. Waters Corporation has provided a project grant to Imperial College for this work.

\section{Consent for publication}

Not applicable.

\section{Ethics approval and consent to participate}

Ethical approval was gained from South East London Research Ethics Committee Reference 11/LO/0686, the East of England - Cambridge East Research Ethics Committee Reference 14/EE/0024 and the project was registered under the Imperial College Tissue Bank. Appropriate informed consent was obtained from all participants in the study.

\section{Publisher's Note}

Springer Nature remains neutral with regard to jurisdictional claims in published maps and institutional affiliations.

\section{Author details \\ 'Department of BioSurgery and Surgical Technology, Imperial College London, London, UK. 'Division of Computational and Systems Medicine, Imperial College, London, UK. ${ }^{3}$ Waters Research Centre, Budapest, Hungary. ${ }^{4}$ Department of Pathology, Imperial College NHS Trust, London, UK. ${ }^{5}$ Sir Alexander Fleming Building, South Kensington Campus, Imperial College, London SW7 2AZ, UK. ${ }^{6}$ Department of BioSurgery and Surgical Technology, Clinical Senior Lecturer and Consultant Breast Surgeon, St Mary's Hospital, 10th Floor, QEQM Wing, London W2 1NY, UK.}

Received: 8 December 2016 Accepted: 25 April 2017

Published online: 23 May 2017

\section{References}

1. Stewart BW, Wild C. World Cancer Report 2014. International Agency for Research on Cancer; 2014. http://publications.iarc.fr/Non-Series-Publications/ World-Cancer-Reports/World-Cancer-Report-2014.

2. DeSantis CE, Lin CC, Mariotto AB, Siegel RL, Stein KD, Kramer JL, Alteri R, Robbins AS, Jemal A. Cancer treatment and survivorship statistics, 2014. CA Cancer J Clin. 2014;64(4):252-71.

3. Jeevan R, Cromwell DA, Trivella M, Lawrence G, Kearins O, Pereira J, Sheppard C, Caddy CM, van der Meulen JHP. Reoperation rates after breast conserving surgery for breast cancer among women in England: retrospective study of hospital episode statistics. BMJ. 2012;345:e4505. http://www.bmj.com/content/345/bmj.e4505.

4. Isaacs AJ, Gemignani ML, Pusic A, Sedrakyan A. Association of breast conservation surgery for cancer with 90-day reoperation rates in New York State. JAMA Surg. 2016;151(7):648-55.
5. Wilke LG, Czechura T, Wang C, Lapin B, Liederbach E, Winchester DP, Yao K. Repeat surgery after breast conservation for the treatment of stage 0 to $\|$ breast carcinoma: a report from the National Cancer Data Base, 2004-2010. JAMA Surg. 2014;149(12):1296-305.

6. Landercasper J, Whitacre E, Degnim AC, Al-Hamadani M. Reasons for re-excision after lumpectomy for breast cancer: insight from the American Society of Breast Surgeons Mastery(SM) database. Ann Surg Oncol. 2014;21(10):3185-91.

7. McCahill LE, Single RM, Bowles EJA, Feigelson HS, James TA, Barney T, Engel $J M$, Onitilo AA. Variability in reexcision following breast conservation surgery. JAMA-J Am Med Assoc. 2012;307(5):467-75.

8. Houssami N, Macaskill P, Marinovich ML, Morrow M. The association of surgical margins and local recurrence in women with early-stage invasive breast cancer treated with breast-conserving therapy: a meta-analysis. Ann Surg Oncol. 2014;21(3):717-30.

9. Moran MS, Schnitt SJ, Giuliano AE, Harris JR, Khan SA, Horton J, Klimberg S, Chavez-MacGregor M, Freedman G, Houssami N, et al. Society of Surgical Oncology-American Society for Radiation Oncology consensus guideline on margins for breast-conserving surgery with whole-breast irradiation in stages I and II invasive breast cancer. Int J Radiat Oncol Biol Phys. 2014;88(3):553-64.

10. Heil J, Breitkreuz K, Golatta M, Czink E, Dahlkamp J, Rom J, Schuetz F, Blumenstein M, Rauch G, Sohn C. Do reexcisions impair aesthetic outcome in breast conservation surgery? Exploratory analysis of a prospective cohort study. Ann Surg Oncol. 2012;19(2):541-7.

11. Xue DQ, Qian C, Yang L, Wang XF. Risk factors for surgical site infections after breast surgery: a systematic review and meta-analysis. Eur J Surg Oncol. 2012;38(5):375-81.

12. Kouzminova NB, Aggarwal S, Aggarwal A, Allo MD, Lin AY. Impact of initial surgical margins and residual cancer upon re-excision on outcome of patients with localized breast cancer. Am J Surg. 2009;198(6):771-80.

13. Abe SE, Hill JS, Han Y, Walsh K, Symanowski JT, Hadzikadic-Gusic L, FlippoMorton T, Sarantou T, Forster M, White Jr RL. Margin re-excision and local recurrence in invasive breast cancer: a cost analysis using a decision tree model. J Surg Oncol. 2015;112(4):443-8.

14. St John ER, Al-Khudairi R, Ashrafian H, Athanasiou T, Takats Z, Hadjiminas DJ, Darzi A, Leff DR. Diagnostic accuracy of intraoperative techniques for margin assessment in breast cancer surgery: a meta-analysis. Ann Surg. 2017;265(2):300-10.

15. Butler-Henderson $\mathrm{K}$, Lee AH, Price RI, Waring K. Intraoperative assessment of margins in breast conserving therapy: a systematic review. Breast. 2014;23(2):112-9.

16. Esbona K, Li Z, Wilke LG. Intraoperative imprint cytology and frozen section pathology for margin assessment in breast conservation surgery: a systematic review. Ann Surg Oncol. 2012;19(10):3236-45.

17. Boughey JC, Hieken TJ, Jakub JW, Degnim AC, Grant CS, Farley DR, Thomsen KM, Osborn JB, Keeney GL, Habermann EB. Impact of analysis of frozen-section margin on reoperation rates in women undergoing lumpectomy for breast cancer: evaluation of the National Surgical Quality Improvement Program data. Surgery. 2014;156(1):190-7.

18. Boughey JC, Keeney GL, Radensky P, Song CP, Habermann EB, Boughey JC, Keeney GL, Radensky P, Song CP, Habermann EB. ReCAP: economic implications of widespread expansion of frozen section margin analysis to guide surgical resection in women with breast cancer undergoing breastconserving surgery. J Oncol Pract. 2016;12(4):e413-22.

19. Ihrai T, Quaranta D, Fouche Y, Machiavello JC, Raoust I, Chapellier C, Maestro C, Marcy M, Ferrero JM, Flipo B. Intraoperative radiological margin assessment in breast-conserving surgery. Eur J Surg Oncol. 2014;40(4):449-53.

20. Krekel NMA, Haloua MH, Lopes Cardozo AMF, de Wit RH, Bosch AM, de Widt-Levert LM, Muller S, van der Veen H, Bergers E, de Lange de Klerk ESM, et al. Intraoperative ultrasound guidance for palpable breast cancer excision (COBALT trial): a multicentre, randomised controlled trial. Lancet Oncol. 2013;14(1):48-54.

21. Weber WP, Engelberger $S$, Viehl $C T$, Zanetti-Dallenbach R, Kuster $S$, Dirnhofer S, Wruk D, Oertli D, Marti WR. Accuracy of frozen section analysis versus specimen radiography during breast-conserving surgery for nonpalpable lesions. World J Surg. 2008;32(12):2599-606.

22. Thill M, Baumann K, Barinoff J. Intraoperative assessment of margins in breast conservative surgery-still in use? J Surg Oncol. 2014;110(1):15-20.

23. Thill M, Dittmer C, Baumann K, Friedrichs K, Blohmer JU. MarginProbe(R)final results of the German post-market study in breast conserving surgery of ductal carcinoma in situ. Breast. 2014;23(1):94-6.

24. Pappo I, Spector R, Schindel A, Morgenstern S, Sandbank J, Leider LT, Schneebaum S, Lelcuk S, Karni T. Diagnostic performance of a novel device 
for real-time margin assessment in lumpectomy specimens. J Surg Res. 2010;160(2):277-81.

25. Dixon JM, Renshaw L, Young O, Kulkarni D, Saleem T, Sarfaty M, Sreenivasan R, Kusnick C, Thomas J, Williams LJ. Intra-operative assessment of excised breast tumour margins using ClearEdge imaging device. Eur J Surg Oncol. 2016:42(12):1834-40

26. Brown JQ, Bydlon TM, Kennedy SA, Caldwell ML, Gallagher JE, Junker M, Wilke LG, Barry WT, Geradts J, Ramanujam N. Optical spectral surveillance of breast tissue landscapes for detection of residual disease in breast tumor margins. PLoS One. 2013;8(7):e69906.

27. Brown JQ, Bydlon TM, Richards LM, Yu B, Kennedy SA, Geradts J, Wilke LG, Junker M, Gallagher J, Barry W, et al. Optical assessment of tumor resection margins in the breast. IEEE J Sel Top Quantum Electron. 2010;16(3):530-44.

28. Kennedy S, Geradts J, Bydlon T, Brown JQ, Gallagher J, Junker M, Barry W, Ramanujam N, Wilke L. Optical breast cancer margin assessment: an observational study of the effects of tissue heterogeneity on optical contrast. Breast Cancer Res. 2010;12(6):R91.

29. Kong K, Zaabar F, Rakha E, Ellis I, Koloydenko A, Notingher I. Towards intraoperative diagnosis of tumours during breast conserving surgery by selectivesampling Raman micro-spectroscopy. Phys Med Biol. 2014;59(20):6141-52.

30. Nguyen FT, Zysk AM, Chaney EJ, Kotynek JG, Oliphant UJ, Bellafiore FJ, Rowland KM, Johnson PA, Boppart SA. Intraoperative evaluation of breast tumor margins with optical coherence tomography. Cancer Res. 2009;69(22):8790-6.

31. Laughney AM, Krishnaswamy V, Rizzo EJ, Schwab MC, Barth RJ, Cuccia DJ, Tromberg BJ, Paulsen KD, Pogue BW, Wells WA. Spectral discrimination of breast pathologies in situusing spatial frequency domain imaging. Breast Cancer Res. 2013;15(4):R61.

32. Tummers Q, Verbeek FP, Schaafsma B, Boonstra MC, Van Der Vorst J, Liefers GJ, Van De Velde CJ, Frangioni JV, Vahrmeijer A. Detection of breast cancer using near-infrared fluorescence imaging and Methylene Blue. Mol Imaging Biol. 2013;1:S363.

33. Chang TP, Leff DR, Shousha S, Hadjiminas DJ, Ramakrishnan R, Hughes MR Yang GZ, Darzi A. Imaging breast cancer morphology using probe-based confocal laser endomicroscopy: towards a real-time intraoperative imaging tool for cavity scanning. Breast Cancer Res Treat. 2015;153(2):299-310.

34. St John ER, Al-Khudairi R, Ashrafian $\mathrm{H}$, et al. Diagnostic accuracy of intraoperative techniques for margin assessment in breast cancer surgery. Ann Surg. 2016;265(2):300-10.

35. Crutchfield CA, Thomas SN, Sokoll L, Chan DW. Advances in mass spectrometry-based clinical biomarker discovery. Clin Proteomics. 2016;13:1.

36. Chung L, Moore K, Phillips L, Boyle FM, Marsh DJ, Baxter RC. Novel serum protein biomarker panel revealed by mass spectrometry and its prognostic value in breast cancer. Breast Cancer Res. 2014;16(3):R63.

37. Kriegsmann J, Kriegsmann M, Casadonte R. MALDI TOF imaging mass spectrometry in clinical pathology: a valuable tool for cancer diagnostics (review). Int J Oncol. 2015;46(3):893-906.

38. Calligaris D, Caragacianu D, Liu X, Norton I, Thompson CJ, Richardson AL, Golshan M, Easterling ML, Santagata S, Dillon DA, et al. Application of desorption electrospray ionization mass spectrometry imaging in breast cancer margin analysis. Proc Natl Acad Sci U S A. 2014;111(42):15184-9.

39. St John ER, Rossi M, Pruski P, Darzi A, Takats Z. Intraoperative tissue identification by mass spectrometric technologies. TrAC Trends Anal Chem. 2016;85(Part A):2-9.

40. St John E, Balog J, Muirhead L, Speller A, Jones E, Ramakrishnan R, Darzi A, Takats Z, Leff D. 11. Intra-operative rapid evaporative ionisation mass spectrometry: a future intelligent knife (iKnife) for oncological margin control? Eur J Surg Oncol. 2015:41(6):S20.

41. Balog J, Sasi-Szabo L, Kinross J, Lewis MR, Muirhead LJ, Veselkov K, Mirnezami R, Dezso B, Damjanovich L, Darzi A, et al. Intraoperative tissue identification using rapid evaporative ionization mass spectrometry. Sci Transl Med. 2013;5(194):194ra193.

42. Schafer KC, Denes J, Albrecht K, Szaniszlo T, Balog J, Skoumal R, Katona M, Toth M, Balogh L, Takats Z. In vivo, in situ tissue analysis using rapid evaporative ionization mass spectrometry. Angew Chem. 2009;48(44):8240-2.

43. Lee AHS, Carder P, Deb R et al. Guidelines for non-operative diagnostic procedures and reporting in breast cancer screening [Royal College of Pathologists web site]. June 1, 2016. Available at: https://www.rcpath.org/ resourceLibrary/g150-non-op-reporting-breast-cancer-screening-feb17-pdf. html. Accessed 01 Dec 2016.

44. Veselkov KA, Lindon JC, Ebbels TMD, Crockford D, Volynkin W, Holmes E, Davies DB, Nicholson JK. Recursive segment-wise peak alignment of biological 1H NMR spectra for improved metabolic biomarker recovery. Anal Chem. 2009;81(1):56-66.

45. Fahy E, Sud M, Cotter D, Subramaniam S. LIPID MAPS online tools for lipid research. Nucleic Acids Res. 2007;35(Web Server issue):W606-12.

46. Smith CA, O'Maille G, Want EJ, Qin C, Trauger SA, Brandon TR, Custodio DE, Abagyan R, Siuzdak G. METLIN: a metabolite mass spectral database. Ther Drug Monit. 2005;27(6):747-51.

47. Sakai K, Okuyama H, Yura J, Takeyama H, Shinagawa N, Tsuruga N, Kato K, Miura K, Kawase K, Tsujimura T, et al. Composition and turnover of phospholipids and neutral lipids in human breast cancer and reference tissues. Carcinogenesis. 1992;13(4):579-84.

48. Guenther S, Muirhead LJ, Speller AV, Golf O, Strittmatter N, Ramakrishnan R, Goldin RD, Jones E, Veselkov K, Nicholson J, et al. Spatially resolved metabolic phenotyping of breast cancer by desorption electrospray ionization mass spectrometry. Cancer Res. 2015;75(9):1828-37.

49. Dolce V, Cappello AR, Lappano R, Maggiolini M. Glycerophospholipid synthesis as a novel drug target against cancer. Curr Mol Pharmacol. 2011;4(3):167-75.

50. Hilvo M, Denkert C, Lehtinen L, Muller B, Brockmoller S, Seppanen-Laakso T, Budczies J, Bucher E, Yetukuri L, Castillo S, et al. Novel theranostic opportunities offered by characterization of altered membrane lipid metabolism in breast cancer progression. Cancer Res. 2011;71(9):3236-45.

51. Moran MS, Schnitt SJ, Giuliano AE, Harris JR, Khan SA, Horton J, Klimberg S, Chavez-MacGregor M, Freedman G, Houssami N, et al. Society of Surgical Oncology-American Society for Radiation Oncology consensus guideline on margins for breast-conserving surgery with whole-breast irradiation in stages I and II invasive breast cancer. J Clin Oncol. 2014;32(14):1507-15.

52. Rosenberger LH, Mamtani A, Fuzesi S, Stempel M, Eaton A, Morrow M, Gemignani ML. Early adoption of the SSO-ASTRO consensus guidelines on margins for breast-conserving surgery with whole-breast irradiation in stage I and II invasive breast cancer: initial experience from Memorial Sloan Kettering Cancer Center. Ann Surg Oncol. 2016;23(10):3239-46.

53. Schulman AM, Mirrielees JA, Leverson G, Landercasper J, Greenberg C, Wilke LG. Reexcision surgery for breast cancer: an analysis of the American Society of Breast Surgeons (ASBrS) MasterySM Database following the SSO-ASTRO "No Ink on Tumor" Guidelines. Ann Surg Oncol. 2017;24(1):52-8.

54. Osako T, Nishimura R, Nishiyama $Y$, Okumura $Y$, Tashima R, Nakano M, Fujisue M, Toyozumi Y, Arima N. Efficacy of intraoperative entirecircumferential frozen section analysis of lumpectomy margins during breast-conserving surgery for breast cancer. Int J Clin Oncol. 2015; 20(6):1093-101.

55. Jorns JM, Daignault S, Sabel MS, Wu AJ. Is intraoperative frozen section analysis of reexcision specimens of value in preventing reoperation in breast-conserving therapy? Am J Clin Pathol. 2014;142(5):601-8.

56. Carels N, Spinasse LB, Tilli TM, Tuszynski JA. Toward precision medicine of breast cancer. Theor Biol Med Model. 2016;13:7.

\section{Submit your next manuscript to BioMed Central and we will help you at every step:}

- We accept pre-submission inquiries

- Our selector tool helps you to find the most relevant journal

- We provide round the clock customer support

- Convenient online submission

- Thorough peer review

- Inclusion in PubMed and all major indexing services

- Maximum visibility for your research

Submit your manuscript at www.biomedcentral.com/submit
Biomed Central 